\title{
Assessment and Prediction of Incidence Trend of Stomach, Colorectal and Esophagus Cancers Using Time-Series Models in Kurdistan, West of Iran
}

\author{
Maryam Parvareh $^{1}$, Satar Rezaei $^{2}$, Daem Roshani $^{3}$, Ebrahim Ghaderi $^{4}$, Bijan Nouri $^{5}$ \\ 1. MSc of Epidemiology, Social Determinants of Health Research Center, Research Institute for Health Development, \\ Kurdistan University of Medical Sciences, Sanandaj, Iran. ORCID ID: 0000-0003-2625-3674 \\ 2. Assistant Professor of Health Economics, Research Center for Environmental Determinants of Health, Kermanshah \\ University of Medical Sciences, Kermanshah, Iran. ORCID ID: 0000-0002-6194-6057 \\ 3. Associate Professor of Biostatistics, Social Determinants of Health Research Center, Research Institute for Health \\ Development, Kurdistan University of Medical Sciences, Sanandaj, Iran. ORCID ID: 0000-0003-4746-1114 \\ 4. Associate Professor of Epidemiology, Social Determinants of Health Research Center, Research Institute for Health \\ Development, Kurdistan University of Medical Sciences, Sanandaj, Iran. ORCID ID: 0000-0002-2303-1657 \\ 5. Assistant Professor of Biostatistics, Social Determinants of Health Research Center, Research Institute for Health \\ Development, Kurdistan University of Medical Sciences, Sanandaj, Iran., (Corresponding Author), Tel: 087-33291100, \\ Email: bijannuri@gmail.com, ORCID ID: 0000-0003-0064-0094
}

\begin{abstract}
Background and Aim: The cancers of the gastrointestinal tract, because of their high prevalence and fatality, are of great importance in most countries like Iran. In terms of prevalence, stomach, esophagus and colorectal cancers in Iran are ranked first, second and eighth, respectively. Therefore, this study aimed to model the incidence of the frequency of new cases of these cancers and their prediction in Kurdistan province, Iran.

Materials and Methods: In this cross-sectional study, the incidence of stomach, esophagus and colorectal cancers were analyzed from April 2000 to March 2017. In order to model time series data of the cancers, the autoregressive integrated moving average (ARIMA) and seasonal autoregressive integrated moving average (SARIMA) with Box-Jenkins approach were applied. After determining the suitable models, the frequencies of new cases for the cancers were predicted until March 2020. Data analysis was performed using R3.4.2 statistical software package.

Results: A total of 6439 gastrointestinal cancers were recorded during the study period, among which stomach, esophagus and colorectal cancers had the highest frequencies with 2548, 1722 and 989 new cases, respectively. The best fited model for stomach, esophagus and colorectal cancers were SARIMA $(0,1,1)(0,0,1)_{4}{ }^{6} \operatorname{SARIMA}(3,1,0)(0,0,1)_{4}$ and ARIMA $(0,1,1)$, respectively. It is predicted that the incidence pattern of these cancers have an upward trend with moderate slope by March 2020.

Conclusion: The high incidence of stomach, colorectal and esophagus cancer, as well as their increasing trend in the predicted time can be a serious alarm. Therefore, in order to prevent and reduce the frequency of these cancers, it is vital to design and implement the effective programs such as screening, especially in high risk groups, early diagnosis of the cancers, increasing public awareness and controlling the risk factors to prevent and reduce of these increasing trends.
\end{abstract}

Keywords: Stomach Cancer, Colorectal Cancer, Esophagus Cancer, Time Series, Kurdistan Received: Nov 8, 2019 Accepted: Dec 30, 2019

How to cite the article: Maryam Parvareh, Satar Rezaei, Daem Roshani, Ebrahim Ghaderi, Bijan Nouri Assessment and prediction of incidence trend of stomach, colorectal and Esophagus cancers using time-series models in Kurdistan, west of Iran. SJKU 2020;25(3):72-86.

Copyright (C) 2018 the Author (s). Published by Kurdistan University of Medical Sciences. This is an open access article distributed under the terms of the Creative Commons Attribution-Non Commercial License 4.0 (CCBYNC), where it is permissible to download, share, remix, transform, and buildup the work provided it is properly cited. The work cannot be used commercially without permission from the journal 


\title{
ارزيابى و يش بينى روند بروز سرطانهاى معده، كلور كتال و مرى با استفاده از مدل سرىهاى زماذى در استان كردستان
}

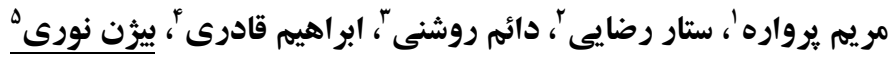 \\ ا. كارشناس ارشد إيدميولوزى، مركز تحقيقات عوامل اجتماعى مؤثر بر سلامت، يُوهشكده توسعه سلامت، دانشكاه علوم يزشكى كردستان، سـندج، ايـران. كـد \\ اركيد: 1.......r-rgrQ-rqVF

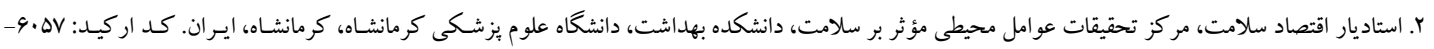 \\ ......... r-9194

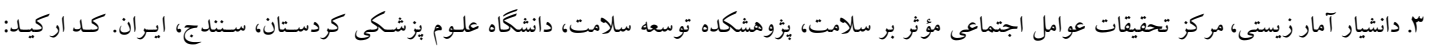 \\ ........r-FVkG-111F

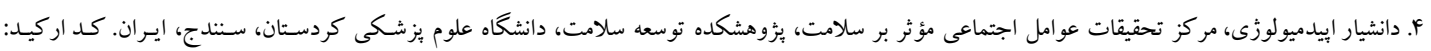 \\ ........r-Yr.r-190V

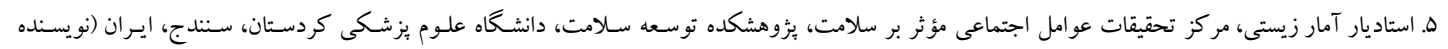

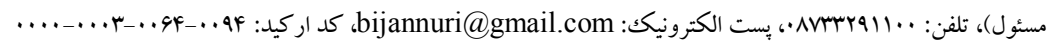

جكيu

زمينه و هدف: سرطانهاى دستكاه گوارش به دليل شيوع بالا و كشندگى زياد از اهميت خاصى در بسيارى از جوامع از جمله

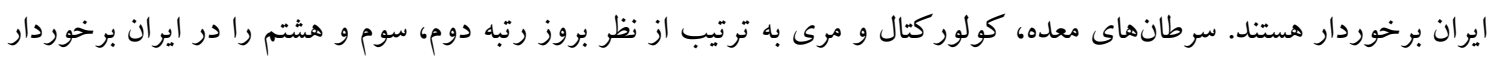

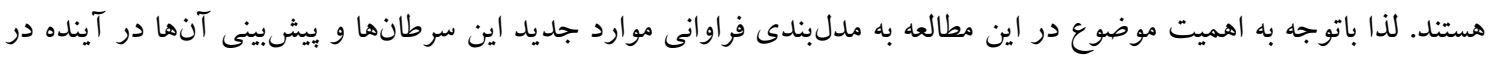
استان كردستان برداخته شد.

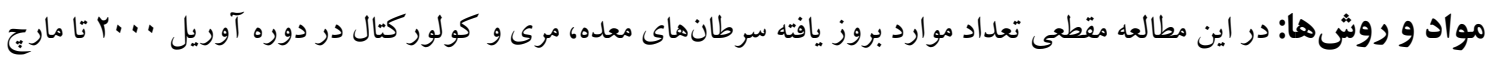

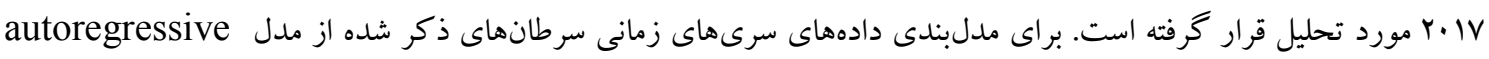
seasonal autoregressive integrated moving average و integrated moving average (ARIMA) با رويكرد Box-Jenkins استفاده شده است. بِ از تعيين مدل مناسب تعداد موارد جديد اين سرطانها تا مارجج

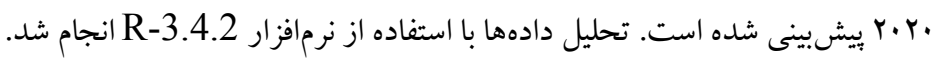

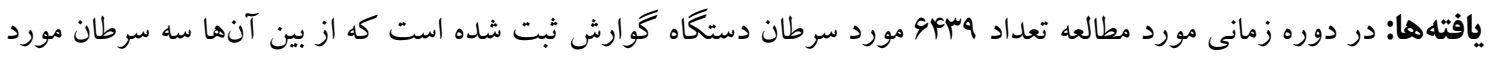
بررسى در اين مطالعه يعنى معده، مرى و كولور كتال بهترتيب با MAFA، IVYY و 9 و مورد بيشترين فراوانى را دارا بودند. بهترين

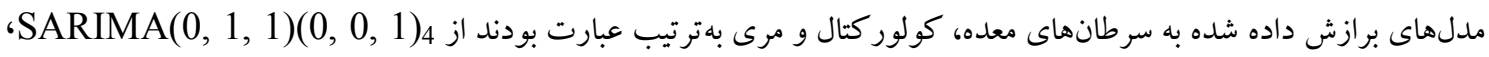

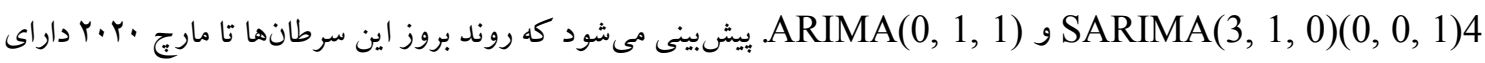

$$
\text { روندى صعودى با شيب ملايم باشند. }
$$

نتيجه كيرى: بروز قابل ملاحظه سرطانهاى معده، كلور كتال و مرى و همجِين روند رو به رشد آنها در زمان يِيشبينى شده

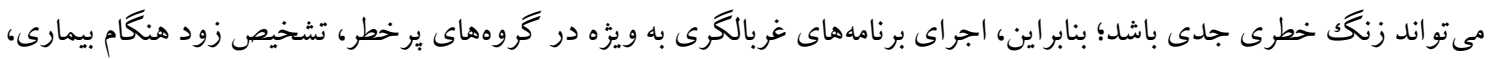

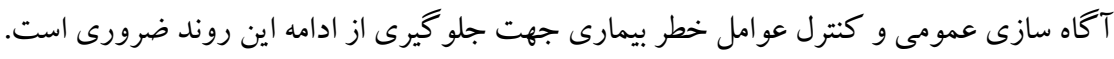
كلمات كليدى: سرطان معده، سرطان كلور كتال، سرطان مرى، سرىهاى زمانى، كردستان وصول مقاله:9//N/IV اصلاحيه نهايى: •9N/9/T بذيرش:9N/1/9 
مى تو انند از عوامل اين تفاوتها در ميزان بروز سرطان معده

سرطان كولوركتال به ترتيب سومين و جهارمين سرطان شايع در مردان و زنان كشور است(|F). تنوع جغرافيايى كستردهاى در ميزان بروز اين سرطان مشاهده مىشود (هان (1). در كشورهاى توسعه يافته ميزان بروز بالاست به طورى كه تقريباً هه درصد از موارد در اين كشورها روى مىدهد؛ اما ايران علىرغم افزايش در ميزان بروز، جزو كشورهاى با

خطر ابتلاى پايين است(19)، 1، ().

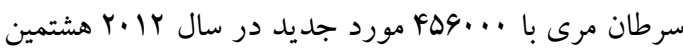

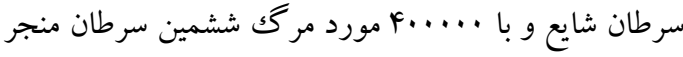
به مرگك در دنياست(1). تخمين زده شده است كه سالانه

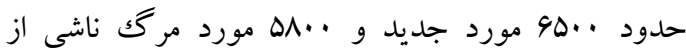
سرطان مرى در كشور روىدهد(س). اين سرطان نيز بالاترين ميزان بروز را در مناطق شمال و شمال غرب كشور

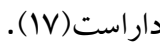

بر اساس آمارهاى واحد يُزوهش سرطان در سازمان جهانى بهداشت، گرجه ميزان بروز سرطانها به طور كلى در

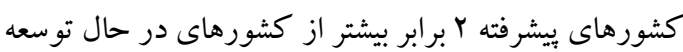

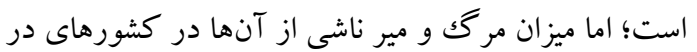
حال توسعه به مراتب بيشتر است(N|). در ايران به عنوان يك كشور درحال توسعه، رشد وضعيت اقتصادى اجتماعى و تغيير الكَوى زندگى سنتى تغييراتى در الكوى بروز سرطانهاى دستگاه گوارش و عوامل خطر مربوط به آنها ايجاد كردهاست. تفاوت در ميزان بروز سرطانهاى معده، مرى و كولوركتال در مناطق مختلف جغرافيايى كشور و تشخيص اكثر موارد بيمارى در مراحل بيشرفته، اهميت يثزوهش در زمينه اين سرطانها را افزايش دادهاست(19، 9). لذا هدف مطالعه حاضر بررسى اييدميولوزى و روند بروز سرطانهاى معده، مرى و كلوركتال با استفاده از مدل سرىهاى زمانى و بيشبينى تعداد موارد جديد آن در آينده است.
مقدمه امروزه در سراسر دنيا سرطانها يكى از اولويتهاى مهم

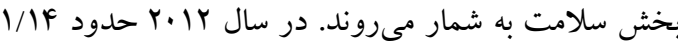
ميليون مورد جديد سرطان و Y/A ميليون مرگك ناشى از آن ثبت شده است(1). با ادامه گذار جهانى دموكرافيك و و اييدميولوزيكك، افزايش بار سرطانها در دهدهاى آينده انتظار مىرود(Y). در ايران سالانه حدود ... .اله مورد جديد سرطان بروز مى كند و ...هr نفر جان خود را بر اثر اين بيمارى از دست مى دهند(ب). از ميان همه سرطانها بدخيمىهاى دستخاه گوارش به علت طيف گسترده و ميزان بروز بالا از اهميت زيادى r. برخوردارند(F). سرطانهاى دستگاه گوارش عامل درصد موارد جديد سرطان و ها درصد موارد مرگكومير ناشى از آن مىباشند(ه). طبق گزارش انجمن سرطان آمريكا سالانه بيش از .... مبتلا مىشوند و تقريباً ....4سا نفر بر اثر آن فوت مى كنند(F). در ايران اين دسته از سرطانها از اهميت زيادى برخوردارند؛ زيرا عامل ^\ درصد موارد كل سرطانها و بيش از •و درصد مرككهاى ناشى از آنها هستند(V، 9). بر آورد شده است كه در ايران اكثريت سرطانهاى دستگاه كوارش در معده سپس كولوركتال، مرى، يانكراس و كبد

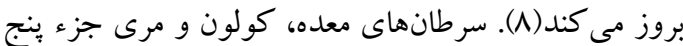
سرطان شايع در مردان و زنان كشور هستند( •(، 9). سرطان معده دومين سرطان شايع در مردان و سومين در زنان ايرانى است(9). علىرغم كاهش جشمخير ميزان بروز

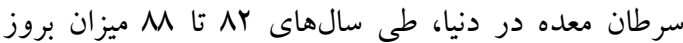
سرطان معده در كل كشور و در هر دو جنس روندى افزايشى داشته كه اين ميزان در مردان حدود دو برابر بيشتر بوده است(Y I، II). در حالى كه مناطق شمال و شمال غرب كشور در معرض خطر زياد سرطان معده قرار دارند؛ اما ديخر مناطق با خطر متوسط و يا كم روبرو هستند(I)). تنوع جغرافيايى و الكوى متنوع زندكى در اقليم يهناور ايران 
Autocorrelation Function or PACF

$$
\text { مى شود. معادله اين مدل بهصورت زير است: }
$$

SARIMA(p.d.q)(P.D.Q) $)_{S}$ :

$$
\Phi_{P}\left(\beta^{s}\right) \varphi_{p}(\beta)(1-
$$

$\left.\beta^{s}\right)^{D}(1-\beta)^{d} Z_{t}=\Theta_{Q}\left(\beta^{s}\right) \theta_{q}(\beta) a_{t}$

كه در آن

$\Phi_{P}\left(\beta^{s}\right)=\left(1-\Phi_{1} \beta^{s}-\cdots-\Phi_{P} \beta^{P s}\right)$,

$\varphi_{p}(\beta)=\left(1-\varphi_{1} \beta-\cdots-\varphi_{p} \beta\right)$,

$\Theta_{Q}\left(\beta^{s}\right)=\left(1-\Theta_{1} \beta^{s}-\cdots-\Theta_{Q} \beta^{Q s}\right)$,

$\theta_{q}(\beta)=\left(1-\theta_{1} \beta-\cdots-\theta_{q} \beta\right)$,

در بسطهاى فوق، $\varphi$ و, $\theta$ بارامترهاى خودهمبستخى و

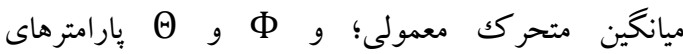
خودهمبستگى و ميانگين متحر كك فصلى هستند. همجنين،

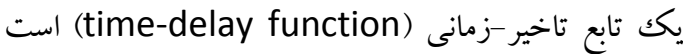

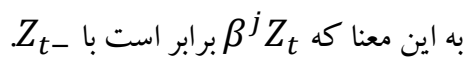

مدلسازى Box-Jenkins شامل جند مرحله متوالى تعبين

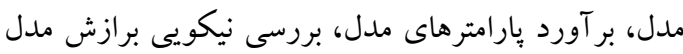

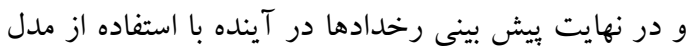
برازش داده شده است. در اولين مرحله با استفاده از آزمون

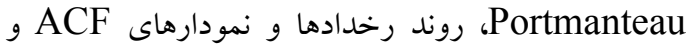
بررسى مى شود كه دادهها white noise هستند و PACF

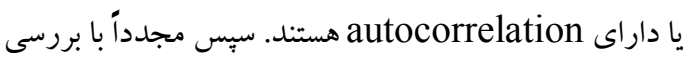
روند رخدادها، نمودارهاى ACF و PACF و آزمون Dickey-Fuller وضعيت بايايى فصلى و غيرفصلى مورد آزمون قرار مى گيرد. درصورت نايستايى از تبديلهاى Box-Cox مىشود. بر اساس تعداد لكَهاى معنىدار ACF و مشخص مىشود و با روش Q P، و مرتبه PACF حداقل مربعات پارامترهاى مدل برآورد مىشود. در مرحله بkaike ) AIC بررسى مدل از شاخصهاى Schwartz ) BIC و (Information Criteria (Bayesian Information Criteria كفايت و نيكويى مدل استفاده مىشود، بهطورى كه مقادير كوخكتر نشان دهنده بهتر بودن مدل هستند. در اين مرحله
مواد و روشها

اين مطالعه مقطعى به منظور تحليل دادههاى سرىهاى زمانى (time-series)

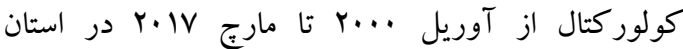
كردستان انجام شد. دادههاى مطالعه از سامانه كشورى ثبت سرطان مركز مديريت بيمارىهاى كشور فراهم شده است. اداره سرطان مركز مديريت بيمارىها به منظور ارتقاء كمى و كيفى روند ثبت سرطان در كثور، از سال Iالب برنامه ثبت مبتنى بر جمعيت را در •r د دانشگاه كشور به عنوان

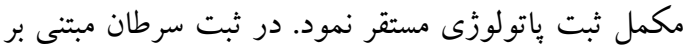

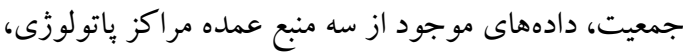
مدارك يز شكى بيمارستانها و اطلاعات مر گك و مير از سال حأ... حذف موارد تكرارى و تطبيق با دادههاى سالهاى كذشته يكك بايگاه داده واحد، جامع و با دقت بالاى كشورى فراهم

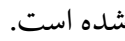

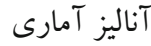
از تحليل سرىهاى زمانى براى مدلبندى فراوانى موارد مشاهده شده سرطانها و ويشبينى بروز موارد جديد در

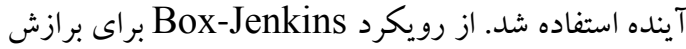
يك مدل Seasonal Autoregressive ) SARIMA (Integrated Moving Average واحد زمان براى هر مشاهده سه ماه متوالى در نظر گرفته شد. SARIMA (p, d, q)(P, بهصورت SARIMA مدل مشخص مى شود كه در آن d و d D بهترتيب D, Q)

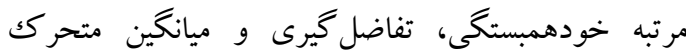

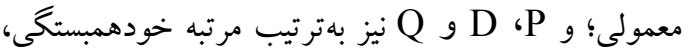
تفاضل گيرى و ميانگين متحرك فصلى هستند، همجنين انديس S دوره فصلى مدل است. مرتبه مذكور غيرفصلى و

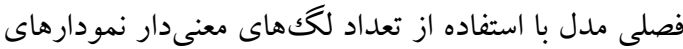
توابع خودهمبستخى ( Autocorrelation Function Partial ) و خودهمبستگى ) (or ACF 
در بازه زمانى مورد مطالعه rADF نفر با تشخيص سرطان معده ثبت شدهاند كه از اين تعداد rاIIا نفر آنها مرد

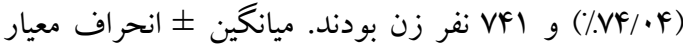
سن تشخيص مردان و زنان مبتلا به سرطان معده بهترتيب برابر r/F/ به سرطان مرى در دو جنس تقريباً مشابه بود به طورى كه از IVFY فرد مبتلا IQ

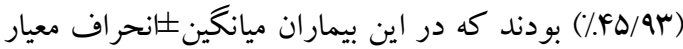

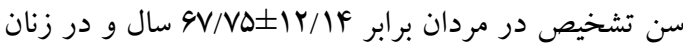
برابر • • سرطان كولور كتال تشخيص داده شد كه شامل ·VI مورد سرطان كولون و rVq مورد سرطان ركتوم است. مردها با

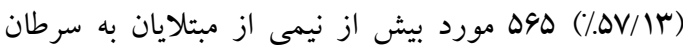
كولور كتال را شامل مىشدند و ميانكين \pm انحراف معيار سن ابتلا به اين سرطان در مردها و زن ها نزديك به هم و

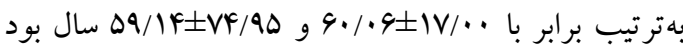
(جدول (). بيشترين فراوانى سرطانهاى معده و كولور كتال

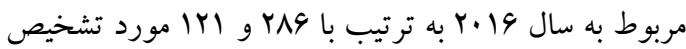
است، همجنين بيشترين مورد تشخيص سرطان مرى مربوط با
همجينين باقيماندهاى مدل نيز مورد ارزيابى قرار مى گيرند. در يكك مدل مناسب باقيماندهها هيج الخوى خاصى ندارند و نمودارهاى ACF و PACF آنها هيج لكَ معنىدارى ندارد، يا به عبارتى باقيمانده ها White noise هستند. درنهايت از مدل فيتشده براى بيشبينى بروز سرطانهاى معده، مرى و كولور كتال تا مارج ·.Y.Y. استفاده شد. تمامى مراحل ذكر شده با استفاده از نرمافزار R-3.4.2 انجام شد. سطح معنى دارى در همه مراحل برابر ه•• > p درنظر كرفته شد.

يافته ها در استان كردستان در دوره زمانى آوريل ....... تا مارج

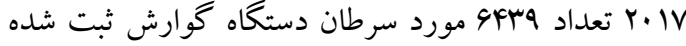
است كه از بين آنها سه سرطان مورد بررسى در اين مطالعه يعنى معده، مرى و كولور كتال بهترتيب با IVYY rOFA و ه/19 مورد بيشترين فراوانى رادر برابر سرطان ساير اركانها دارا بودند. فراوانى هريكك از سرطانهاى دستگاه گوارش به همراه توزيع سنى و جنسى افراد مبتلا در جدول ا آورده شده است.

\begin{tabular}{|c|c|c|c|}
\hline ميانكين士انحراف معيار & مذكر(\%) & تعداد(\%) & \\
\hline $9 V / \cdot F \pm 1 r / 9 r$ & $r \operatorname{llr}(V F / \cdot F)$ & YADF $(F F / K Y)$ & معده \\
\hline $99 / \Delta \Lambda \pm 1 Y / 1 \Lambda$ & $Q T /(\Delta F / \cdot V)$ & IVYr (YG/VF) & مرى \\
\hline$\Delta q / 9 r \pm 19 / 10$ & $\Delta 9 \Delta(\Delta V / I r)$ & $919(10 / r 4)$ & كلور كتال \\
\hline $99 / 4 Y \pm 19 / 94$ & IFV (DV/AV) & rQF $(r / 9 F)$ & كبد \\
\hline$q 1 / / V \pm \mid r / 4 \pi$ & $\Lambda r(\Delta Q / \mathcal{A r})$ & $\mid r \wedge(Y / \mid F)$ & يانكراس \\
\hline$\Delta \varphi / \Lambda \Delta \pm / r / V \Lambda$ & $V \varphi(\Delta \Delta / \Lambda \Lambda)$ & 1 1rq $(r / 11)$ & ركتوسيكموئيد \\
\hline $9 \cdot / A Y \pm 19 / 0 \Lambda$ & $\Lambda \cdot(9 Y / \Delta \cdot)$ & $1 Y \wedge(1 / 99)$ & روده باريك \\
\hline $9 \% / .4 \pm 19 / \cdot 4$ & rq (rq/...) & $1 \cdots(1 / \Delta \Delta)$ & كيسه صفرا \\
\hline$\Delta \Lambda / V \Lambda \pm I \Delta / q \mu$ & $r \cdot(\Delta F / \cdot \Delta)$ & $r v(\cdot / \Delta v)$ & مقعد \\
\hline$\Delta 4 / \cdots \pm 1 r / \Delta \varphi$ & $r \cdot(9 r / \Delta \cdot)$ & $\operatorname{rr}(\cdot / \Delta \cdot)$ & مجارى صفر' \\
\hline $91 / Y \wedge \pm 19 / 14$ & $r \cdot(q 1 / r r)$ & $4 q(\cdot / V 4)$ & ساير اركانها \\
\hline $9 \Delta / 19 \pm 1 \% / 1 \Delta$ & $41 \cdots(9 r / 9 V)$ & akra & كل \\
\hline
\end{tabular}


Vي بيثن نواى

جدول r. تعداد موارد بروز يافته سرطانهاى معده، مرى و كلور كتال از سال r ماه انتهايى .... ميلادى تا دو ماه ابتدايى سال $r \cdot 1 r$

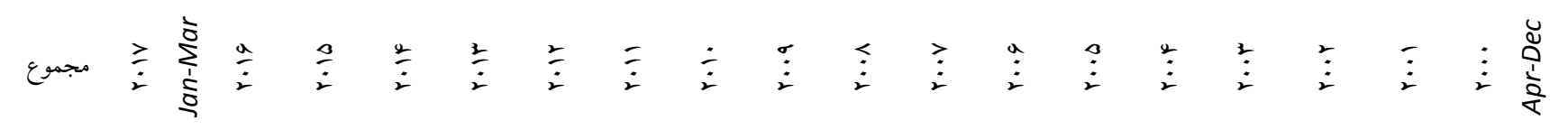

\begin{tabular}{|c|c|c|c|c|c|c|c|c|c|c|c|c|c|c|c|c|c|c|c|}
\hline YADF & VY & YAG & $r \cdot r$ & YFA & $\mid F A$ & 194 & 119 & 194 & 194 & MTY & 109 & $1 . r$ & IVT & $1 \Delta r$ & ITS & Ar & 1.9 & $9 \pi$ & معده \\
\hline IVYY & rی & If. & $1 \ldots$ & $11 \mathrm{~V}$ & $11 \%$ & 1.4 & 1.1 & $1 \ldots$ & $|r|$ & $1 \mathrm{kr}$ & 99 & $1 \ldots$ & 99 & $1 . r$ & 94 & 99 & 99 & Fo & مرى \\
\hline १८१ & rV & $|r|$ & 99 & 99 & $\Lambda r$ & 99 & v. & $\Delta \Lambda$ & 99 & $V F$ & Fq & $\mu F$ & rV & FA & If & 19 & 19 & 11 & كلور كتال \\
\hline
\end{tabular}

و هو درصد در نمودار ات نمايش داده شده است. نمودارهاى PACF ،ACF و روند باقيماندههاى مدل نشان مىدهد كه باقيماندهها White noise اث الى اج). آزمون Portmanteau باقيماندهها نيز نتوانست فرض نيكوئى برازش مدل را رد كند (هسN/ = p p). تعيين مدل و ييشبينى سرطان مرى: روند فراوانى موارد تشخيص يافته سرطان مرى در طول بازه

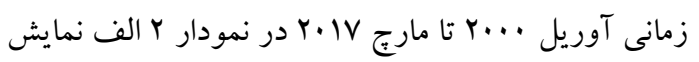
داده شده است. از نمودارهاى PACF ACF كه در نمودارهاى rب و بإ نمايش داده شده است بيداست كه الكوى سرطان مرى داراى يكك الكوى غير فصلى است. آزمون Dickey-Fuller با تائيد فرض نا ايستايى در ميانگين لزوم انجام يككبار تفاضل گيرى را نشان

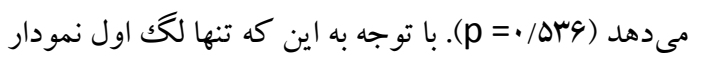
ARIMA(0, معنى ACF

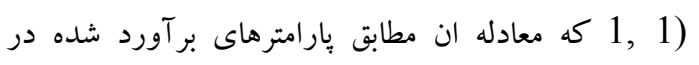

$$
\text { جدول rبه صورت زير است. }
$$

مقادير ييشبينى شده سرطان مرى با استفاده از اين مدل در جدول f ارائه شده است، همجنين روند آنها را بههمراه فاصله اطمينان هاى •9 و هو درصد در نمودار بات نمايش دادهايم. روند باقيماندههاى مدل و عدم معنىدارى لكَ هاى اصني نمودارهاى ACF و PACF باقيماندهها در نمودارهاى
تعيين مدل و بيش بينى سرطان معده:

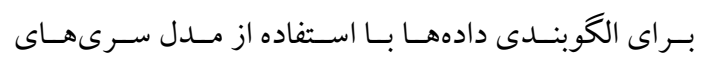
زمـانى ARIMA، ربـع سـال بـهـعنـوان واحســ زمـانى در نظـر گرفتـه شـــ لـذا دادههـاى مـورد مطالعـه كـه از آوريـل F r...

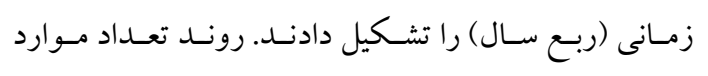

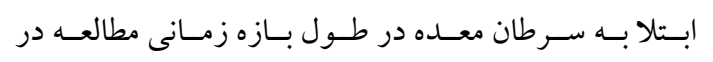
نمــودار الـف نمـايش داده شـده اسـتـ. از ايسن نمـودار

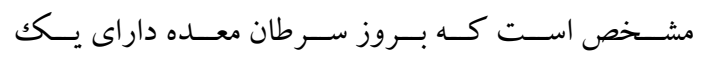
الخــوى فصـلى اسـت بـهـ طـورى كـه عمومـاً در ربـع دوم

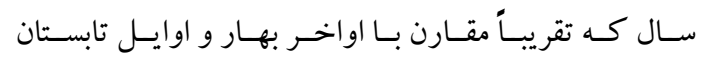
اسـت بـه اوج مسىرسـد. از لـكَهــاى دو نمـودار ACF و PACF

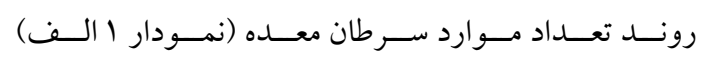

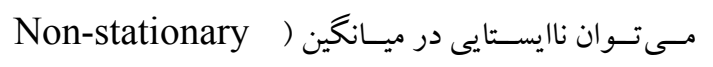

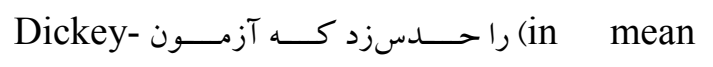
Fuller

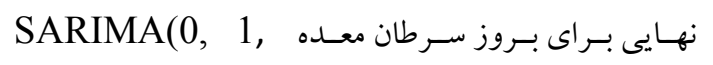

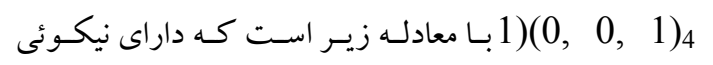

$$
\begin{aligned}
\text { برازش بهتر است (جدول r). } \\
Z_{t}=Z_{t-1}+a_{t}+0.508 a_{t-1}+
\end{aligned}
$$$$
0.203 a_{t-4}+0.103 a_{t-5}
$$

با استفاده از مدل فيت شده فراوانى موارد جديد سرطان

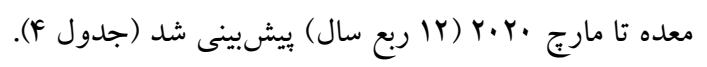
ه. روند مقادير بيشبينى شده به همر اه فاصله هاى بيشبينى 
(0, 0, 1$)_{4}$ جدول r بهصورت زير نوشته مى شود. $Z_{t}=0.223 Z_{t-1}+0.176 Z_{t-2}-$ $0.097 Z_{t-3}+0.698 Z_{t-4}+a_{t}+0.564 a_{t-4}$

با استفاده از مدل فوق فراوانى موارد جديد سرطان

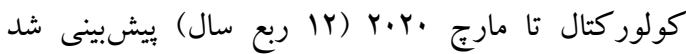
(جدول F) و روند مقادير ويشبينى شده به همر اه فاصله هاى ييشبينى •q و هو درصد در نمودار سات نمايش داده شده

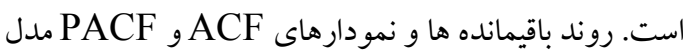
فيت شده هيج الكوى خاصى را نشان نمى دهند كه هماند الند

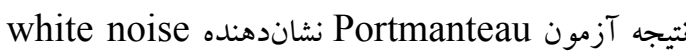

rث تا r تج دال بر كفايت مدل است كه با آزمون Portmanteau تعيين مدل و بيش بينى سرطان كولور كتال:

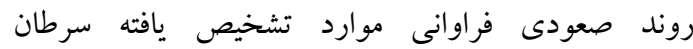

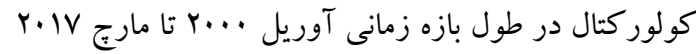
در نمودار ب الف، ميرايى كند نمودارهاى ACF و PACF اين بيمارى در نمودارهاى باب و بٍّ و نتيجه آزمون نشان دهنده وجود نايستايى در ميانگين Dickey-Fuller

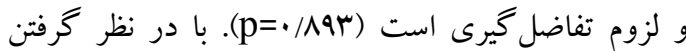
بهنوان شاخصهاى نيكويى برازش، SARIMA(3, 1, مناسبترين مدل براى اين بيمارى

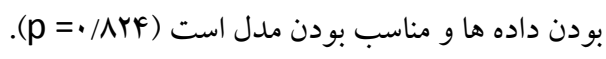

\begin{tabular}{|c|c|c|c|c|c|}
\hline BIC & AIC & SE & ضرايب & هار امترها & سرطان \\
\hline \multirow[t]{2}{*}{$\Delta r q / 99$} & \multirow[t]{2}{*}{$\Delta \mu r / . \Delta$} & $\cdot / 179$ & $-\cdot / \Delta \cdot \Lambda$ & MA1 & \multirow[t]{2}{*}{ معده } \\
\hline & & ./1Y4 & $-\cdot / r \cdot r$ & SMA1 & \\
\hline$r 9 N / r \Lambda$ & $191 / 9 \mathrm{~V}$ & $\cdot / \cdot \Lambda$ & $-\cdot /$ ASV & MA1 & مرى \\
\hline \multirow{4}{*}{ FIG/V9 } & \multirow{4}{*}{$r \cdot r / \Delta r$} & . /TrD & $-\cdot / \mathrm{WV}$ & & \multirow{4}{*}{ كلور كتال } \\
\hline & & . / ब4r &.$- / 9.1$ & AR2 & \\
\hline & &.$/ 194$ &.$- / 991$ & AR3 & \\
\hline & &.$/ 499$ & $-\cdot / \Delta G F$ & SMA1 & \\
\hline
\end{tabular}

جدول †. يويشبينى بروز موارد جديد سرطانهاى معده، مرى و كلور كتال برحسب بازههاى زمانى سه ماهه

\begin{tabular}{|c|c|c|c|}
\hline سرطان كلور كتال & سرطان مرى & سرطان معده & زمان \\
\hline$M F / l q$ & MT/FF & $91 / 14$ & $r \cdot 1 v q 2$ \\
\hline HI/NA & IT/NI & $V I / 4 A$ & $r .1 v q 3$ \\
\hline$\mu / / r$. & $\mathrm{rr} / 91$ & $9 \Lambda / \cdot 1$ & r. IV q4 \\
\hline$r q / \mathrm{VI}$ & $M F / Y \Delta$ & $99 / 14$ & r.१^ q1 \\
\hline$\mu K / Y$. & $\mathrm{rF} / \Delta \mathrm{H}$ & $99 / 11$ & $r \cdot 1 \wedge \mathrm{q} 2$ \\
\hline וT/M & $\mu F / A$. & $9 \mathrm{~V} / 11$ & $r \cdot 1 \wedge \mathrm{q} 3$ \\
\hline$\mu r / 94$ & $r \Delta / \cdot v$ & $9 \mathrm{~V} / 11$ & r.१^ q4 \\
\hline$\mu Y / \cdot \Lambda$ & $r \Delta / r \Delta$ & $9 \mathrm{~V} / 11$ & r.19 q1 \\
\hline$r \Delta / . r$ & $r \Delta / 91$ & $9 V / 11$ & $r .19 q 2$ \\
\hline HF/VF & $r \Delta / \Lambda \Lambda$ & $9 \mathrm{~V} / 11$ & $r .19 \mathrm{q} 3$ \\
\hline
\end{tabular}




\begin{tabular}{llll}
\hline$r \Delta / \Delta \Lambda$ & $r q / 10$ & $9 V / 11$ & $r \cdot 19 \mathrm{q} 4$ \\
$r F / r \Delta$ & $r q / 4 r$ & $9 V / 11$ & $r \cdot r \cdot q 1$
\end{tabular}
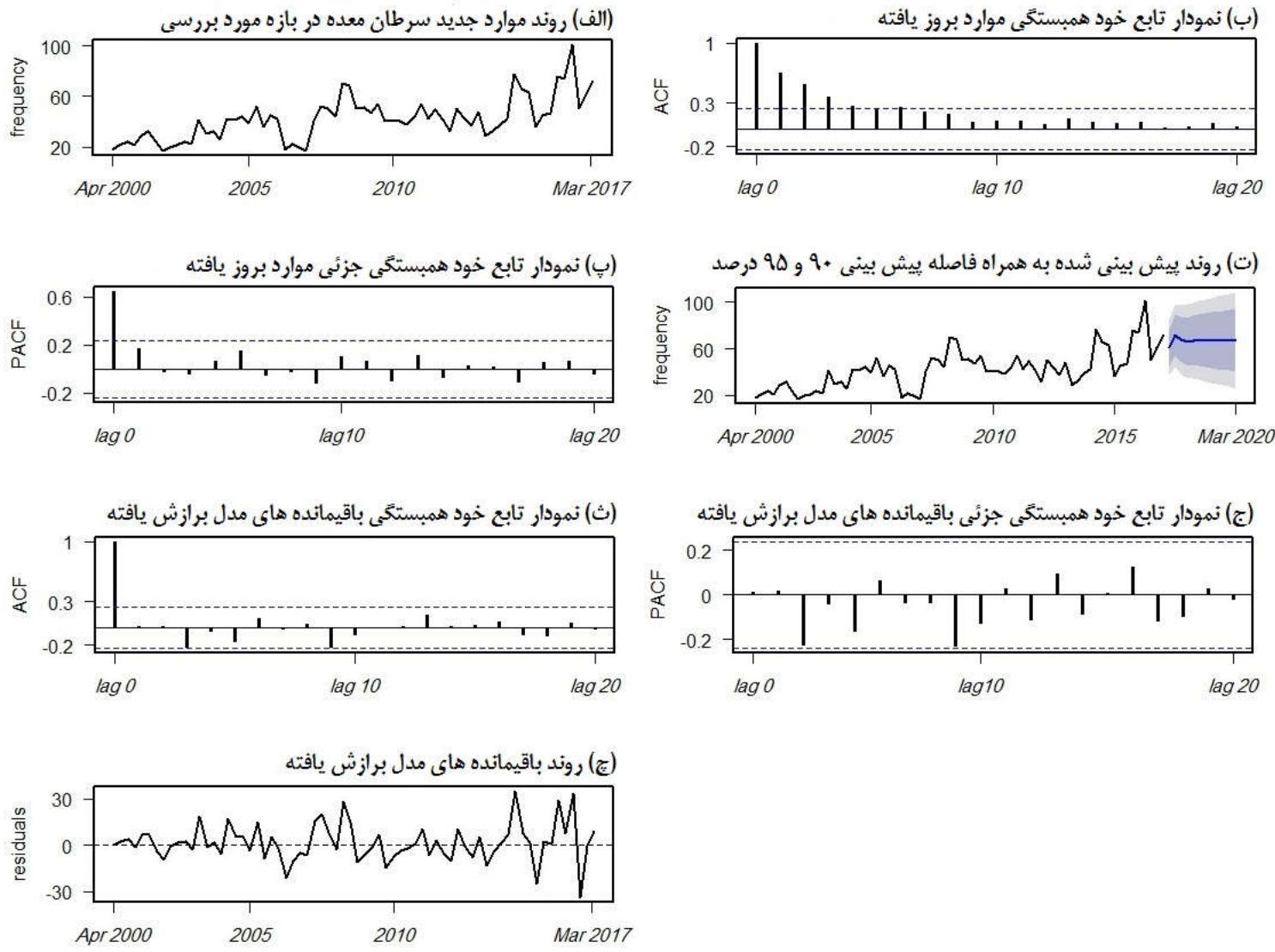

\footnotetext{
نمودار ا. مجموعه نمودارهاى بكار رفته براى تشخيص مدل مناسب سرى زمانى سرطان معده و نمودارهاى مربوط به بررسى نيك

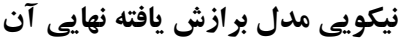



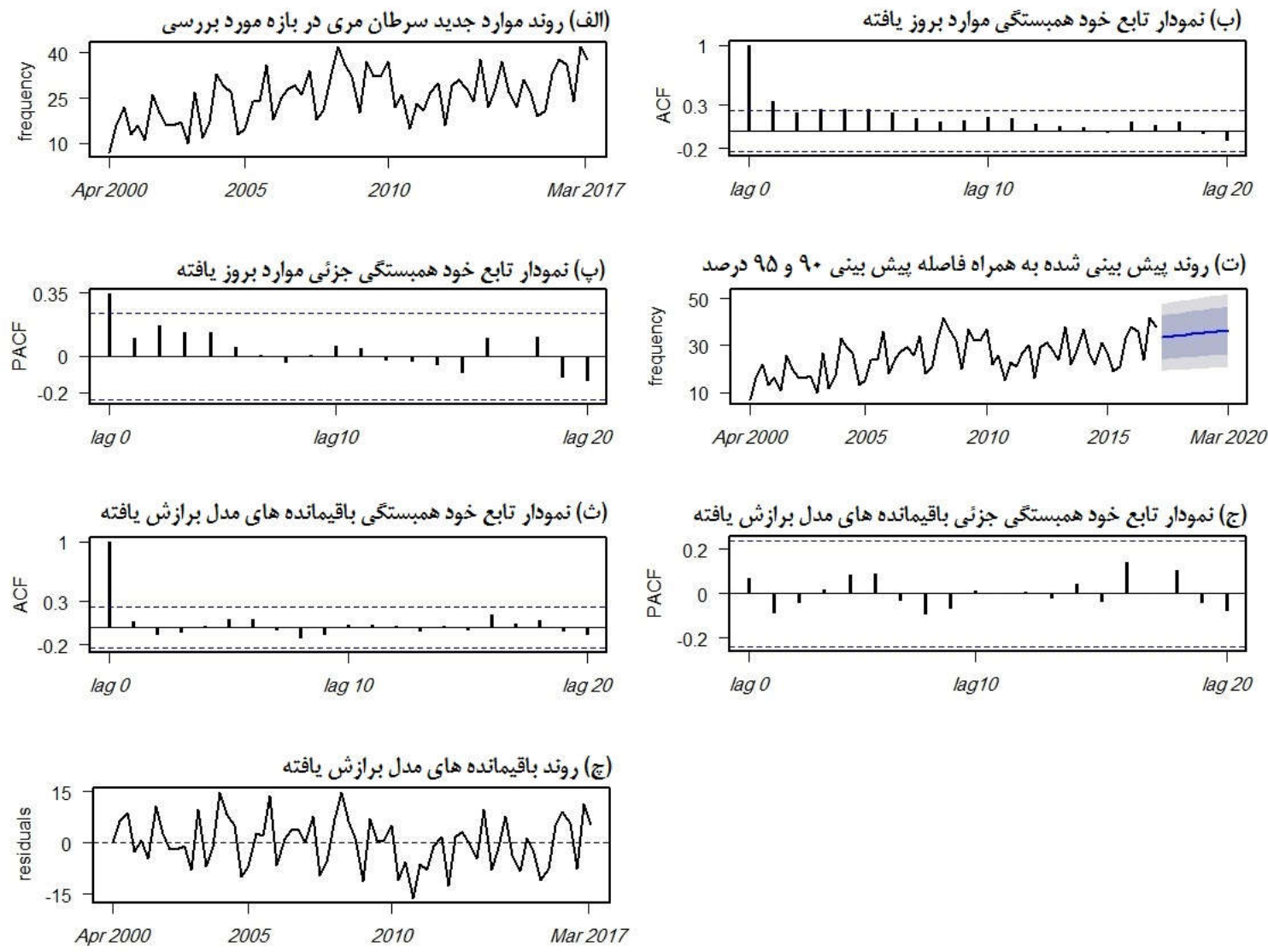

نمودار rا. مجموعه نمودارهاى بكار رفته براى تشخيص مدل مناسب سرى زمانى سرطان مرى و نمودارهاى مربوط به بررسى نيكويى

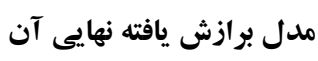



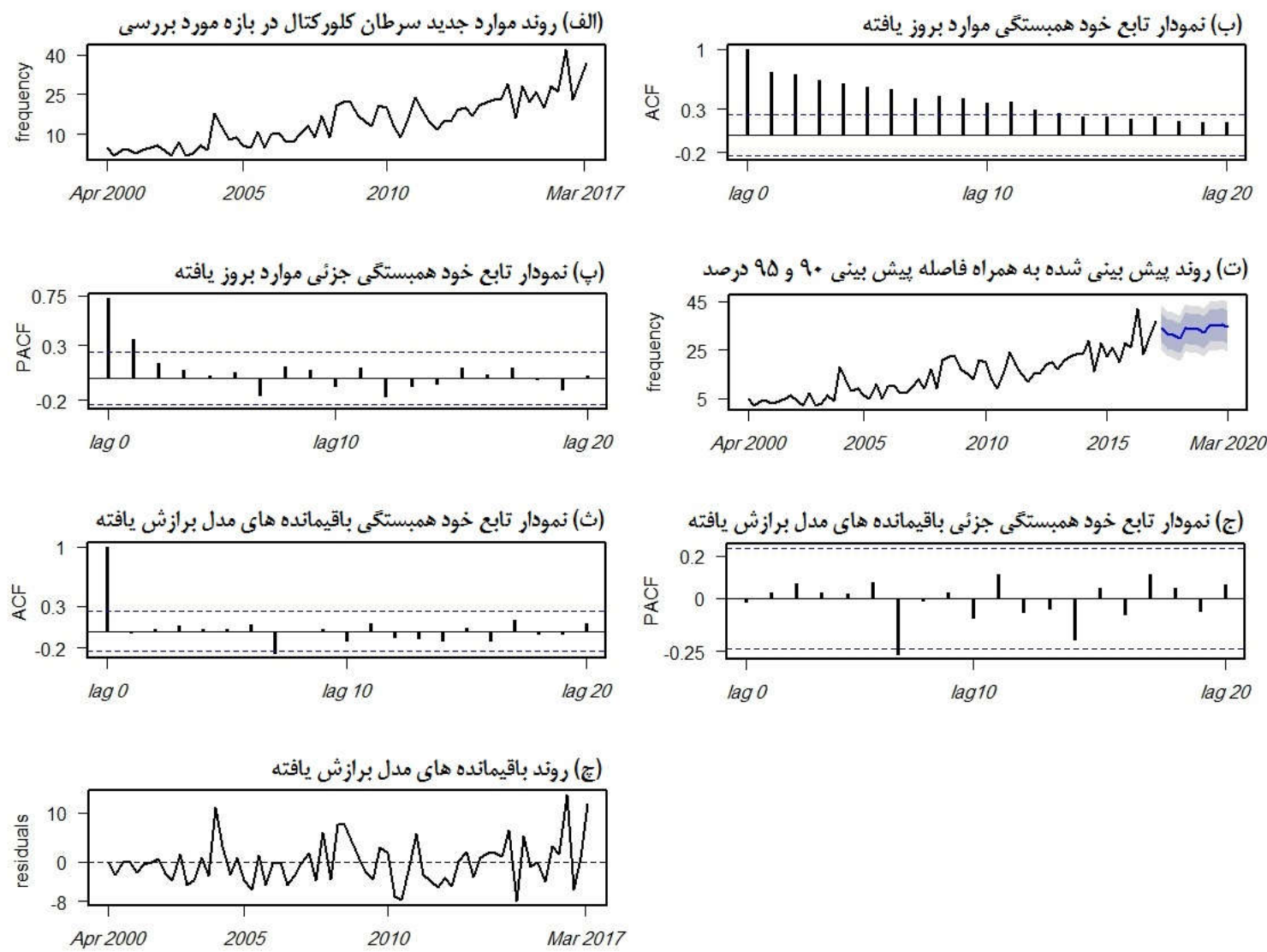

نمودار r. مجموعه نمودارهاى بكار رفته براى تشخيص مدل مناسب سرى زمانى سرطان كلور كتال و نمودارهاى مربوط به بررسى

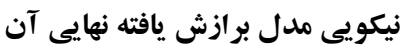

مىدهد (Y). آسياى شرقى، اروياى شرقى و بخش هايى از آمريكاى مركزى و جنوبى نواحى يرخطر براى اين سرطان نتايج نشان مىدهد روند اين سرطانها در طى سالهاى

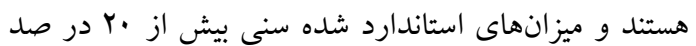
مطالعه افزايش يافته است. موارد سرطان معده از او مورد در هزار نفر است(Y). در مقابل ميزان بروز آن در جنوب آسيا، سه ماهله دوم سال IV Y.IV بل مورد در سه ماهه اول سال شمال و شرق آفريقا، آمريكاى شمالى و اروياى غربى بايين r.r.r. افزايش يافته است. موارد سرطان مرى در طى اين است(YI). توزيع جغرافيايى سرطان معده الكوى مشخصى مدت از سه مورد به وب تغيير كرده است. موارد سرطان ندارد؛ براى مثال با وجود كشورهايى با بالاترين خطر مانند كولور كتال با و جود افزايش در طول سالهاى بيشبينى،

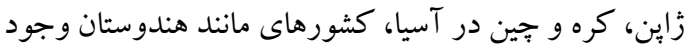
نوسان زيادى داشته است. شيب تغييرات موارد سرطان معده دارند كه ميزان هاى نسبتاً بإينى دارند (Y)

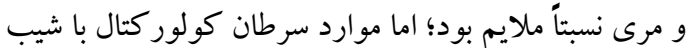

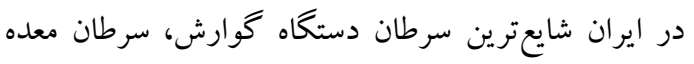

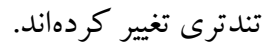
است(Tr، YY). در مقايسه با كشورهاى غربى ميزان بروز در رخداد بيمارى سرطان معده در نقاط مختلف جهان متفاوت ايران بسيار بالاست (19/19 در صد هزار نفر در مردان و · ل1

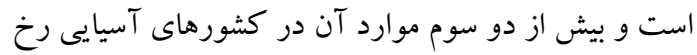


سمت مواد غذايى نمكك سود و كم فيبر است. Y) بهبود روشهاى تشخيصى، افزايش آكاهى عمومى و حساسيت يزشكان نسبت به تشخيص زودرس و بهبود در كيفيت

$$
\text { سيستم ثبت سرطان است (Y9). }
$$

سرطان كولور كتال در كشورهاى در حال توسعه در مقايسه با توسعه يافته شيوع كمترى دارد(F). اروياى غربى، شمال آمريكا، استر اليا و نيوزيلند با ميزان بروز استاندارد سنى FF/A و و Y Y در صد هزار نفر به ترتيب در مردان و زنان بالاترين و غرب آفريقا با ه/ F و م/ در صد هزار نفر بهترتيب در

مردان و زنان كمترين ميز ان بروز را دارند(1). بر اساس آخرين گز ارش كشورى مركز ثبت سرطان در سال

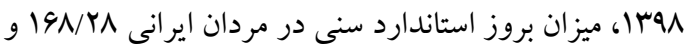
در زنان اكرجه ميزان بروز سرطان كولور كتال در ايران به ويزه در كروه هاى سنى بالا نسبت به متوسط جهانى يايين است؛ اما در طى سه دهه كذشته، روند افزايشى قابل ملاحظهاى داشته است(Y)، (F). نظام ثبت سرطان جمعيتى نشان مىدهد كه ميزان بروز اين بيمارى در استانهاى شمالى، مركزى و غربى بالا و استانهاى جنوب شرقى كمتر است( •r). نتايج مطالعه حاضر ترك نشان داد، روند سرطان كولور كتال در استان كردستان با شيب تندى افزايش بيدا كرده است و در آينده نيز اين روند ادامه دارد. نتايج مطالعه اديب فر در غرب كشور كه بر اساس داده هاى مبتنى بر ياتولوزى بود، نشان داد، ميز ان بروز سرطان كولوركتال در استان كردستان در طى سالهاى

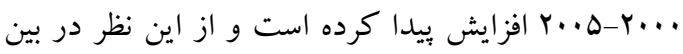
استانهاى غربى (كرمانشاه، كردستان، همدان و ايلام) رتبه دوم را داشته است(آ). مطالعات در ساير استانهاى كشور نيز نتايج مشابهى را گزارش كردهاند. در گيلان در شمال

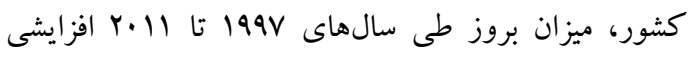
بود(f). مطالعه نجفى در كرمانشاه در غرب كشور نشان داد، طى سالهاى سو199 تا V.... ميزان بروز سرطان كولوركتال سالانه If درصد افزايش ييدا كرده است(YN). در مطالعه يزدانفر در تهران و شيراز (مركز و جنوب غربى كشور) نشان
در صد هزار نفر در زنان در سال INAV و تنوع جغرافيايى كستردهاى در آن مشاهده مىشود(F)، FF). مناطق شمال و شمال غربى (استانهاى اردبيل، سمنان، گَلستان، آذربايجان شرقى و تهران) بالاترين خطر ابتلا به سرطان معده را دارند، استانهاى غربى و مركزى خطر متوسط و مناطق جنوبى مانند كرمان كمترين خطر ابتلا را دارند(ه广، 19). در دهلهاى گذشته بروز و ميرايى سرطان معده در آمريكاو ارويا به طور قابل ملاحظهاى كاهش يافته است. اين كاهش در كشورهاى در حال توسعه خيلى كند صورت مى گيرد(Y). در ايران بيشتر مطالعات روند ميزان بروز سرطان معده را صعودى گزارش كردهاند(·) (1). حيدرى و همكاران نشان دادند بروز كلى سرطان معده از / Y در صد

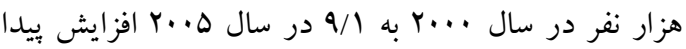
كرده است(Y4). سجادى در اردبيل و مراديور در اصفهان افزايش در ميزان بروز را نشان دادند(YV، ه). در مطالعه ديخر در تهران و شيراز نشان داده شد كه بروز كلى سرطان معده در طى •r سال گذخته اندكى افزايش داشته است (r) درصد در تهران و ها درصد در شيراز)(19). هماهنگ با نتايج مطالعات ذكر شده، در كردستان روند سرطان معده طى سالهاى بيشبينى نيز اين روند را تا سال •r.r.r نشان داد. اين نتايج با مطالعات در برخى از استانها متناقض بود. در مطالعه صومى در استان آذربايجان شرقى كه مبتنى بر دادههاى ياتولوزى

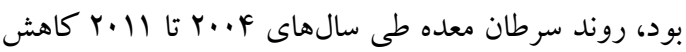

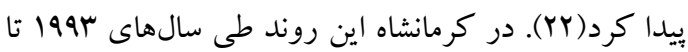

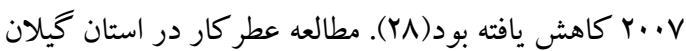
نشان داد كه ميزان بروز سرطانهاى مرى و معده در طى ها 10 سال با روند نسبتاً ثابتى كاهش يافته است(f). به دو دليل عمده براى افزايش ميزان بروز سرطان معده در استان كردستان مىتوان اشاره نمود، هر جند نياز است در مطالعات آينده اين موضوع بررسى گردد: () افزايش ميزان مواجهه با عوامل خطر اين سرطان كه عمدتاً شامل افزايش شيوع عفونت هليكوباكتر بيلورى و تغيير در الكوى غذايى به 
در مطالعه حاضر، روند سرطان مرى در طى سالهاى مطالعه و تا سال · ·. Pعودى بود كه با نتايج مطالعه مراديور در اصفهان و دارابى در كل كشور هماهنگك بود؛ اما با روند ميزان بروز در جمعيت تركمنهاى استان كَلستان، گيلان،

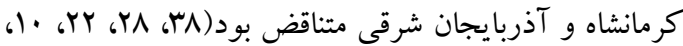
ه، F). بر اساس مطالعه انجام گرفته، كنبد كاوس با ميزان بروز استاندارد شده ..1 در يكك صد هزار نفر، يكى از يرخطرترين مناطق دنياست در حالى كه استان كرمان با بروز استاندارد شدهى حدوداً س در يكك صد هزار نفر، جزو مناطق بسيار كم خطر دنياست(ها). به طور كلى از نظر جغرافيايى وقوع سرطان مرى در دنيا، توزيع يكنواختى ندارد. در مناطق محدود نيز در كنار كانون هايى از مناطق با بروز بسيار بالا مناطقى با ميزان بروز كم وجود دارد. اين تفاوت مىتواند ناشى از عوامل محيطى و يا زنتيكى باشد. در طى ده سال كذشته مطالعات متعدد علل ريسك ابتلاى بالا در شمال شرقى ايران را بررسى كردند. مصرف ¥اى داغ، عدم مصرف كافى ميوه و سبزىها، مصرف مواد مخدر، مصرف آب ناسالم و فقر به عنوان دلايل اصلى شناسايى شدند. به علاوه فاكتورهاى زُنتيكى در ميان جمعيت آن منطقه به عنوان دليل ديخر شيوع بالا اين سرطان گزارش شد( ·1). مطالعه حاضر از معدود مطالعات كشور است كه در آن بر اساس دادههاى مركز ثبت سرطان مبتنى بر جمعيت و با

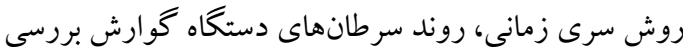
شده است. در كشورهاى در حال توسعه كه دستيابى به دادهها مشكل است و ثبت مبتنى بر جمعيت موارد سرطان كامل شكل نگر فته است، انجام اين گونه مطالعات ارزشمند

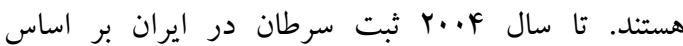
كزارشهاى ياتولوزى بود. بعد از اين زمان ثبت سرطان مبتنى بر جمعيت در كشور گسترش يافت؛ بنابراين اخرجّه ممكن است نتايج اين مطالعه با كم شمارى همراه باشد؛ اما نتايج آن در ترسيم نمايى از وضعيت سرطانهاى دستگاه كوارش، كمكك به برنامه ريزىهاى بهداشتى و طراحى لري برنامهاى بيشخيرى و غربالخرى اهميت دارد. به علت
داده شد كه بروز كلى در طى •r سال كذشته، 90 درصد در شيراز و Ar درصد در تهران افزايش داشته است(19). در كرمان در جنوب كشور در طول يكك دهه (rו.r-r.r.r) ميزان بروز روند صعودى داشته است(Yr). به نظر مىرسد، با وجود تفاوت خطر ابتلا در مناطق مختلف كشور، ميزان بروز در آنها در حال افزايش است، اين در حالى است كه در كل جمعيت آمريكا و در مردان ارويايى بروز در حال كاهش است(سM). بر اساس نتايج اين مطالعه و مطالعات مشابه، افزايش جشم گير سرطان كولوركتال در جمعيت ايرانى قابل بيشبينى است؛ همجنين ميز ان بروز در گرووهاى سنى جوان كشور در حال نزديك شدن به ميزان كشورهاى غربى است كه منجر به افزايش بار بيمارى در آينده نزديك خواهد شد(MF). اكرجهه اين مطالعه به منظور شناسايى دقيق علت افزايش موارد سرطان كولوركتال طراحى نشده است؛ اما اين فرضيه ها مطرح هستند كه سطح اقتصادى-اجتماعى بالا، تغييرات جمعيتى - افزايش ميانهى سنى، مهاجرت از مناطق كم خطر به مناطق برخطر - تغيير در الكوى رفتارى مردم - تغذيه، جاقى و سيكار - شركت در برنامههاى غربالخرى، يراكندگى در دسترسى به خدمات بهداشتى و درمانى مى تو انند تأثير كذار باشند. بيش از •^ درصد موارد بروز و مركَ از سرطان مرى در كشورهاى در حال توسعه رخ مى دهد و ميزان بروز اين نوع سرطان در دنيا رو به افزايش است(ها). برآورد شده تا سال ها.r.r ميلادى، شيوع اين نوع سرطان در كشورهاى بيشرفته DQF درصد افزايش يابد(r). در آمريكاى شمالى و اروياى غربى همزمان با كاهش شيوع سرطان نوع سنخفرشى، نوع آدنو كارسينوما انتهاى مرى رو به افزايش است(r). در كشورهاى در حال توسعه مانند جين و ايران سرطان نوع آدنو كارسينوما در حال افزايش است(4س). ايران به عنوان يكى از كشورهاى قرار گرفته روى كمربند سرطان مرى با ميزان بروز بسيار بالاى اين بيمارى شناخته شده است(rV).

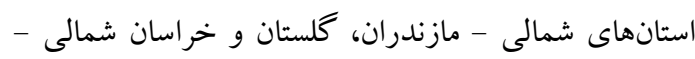
ميزان بروز بالايى دارند(·) (1). 


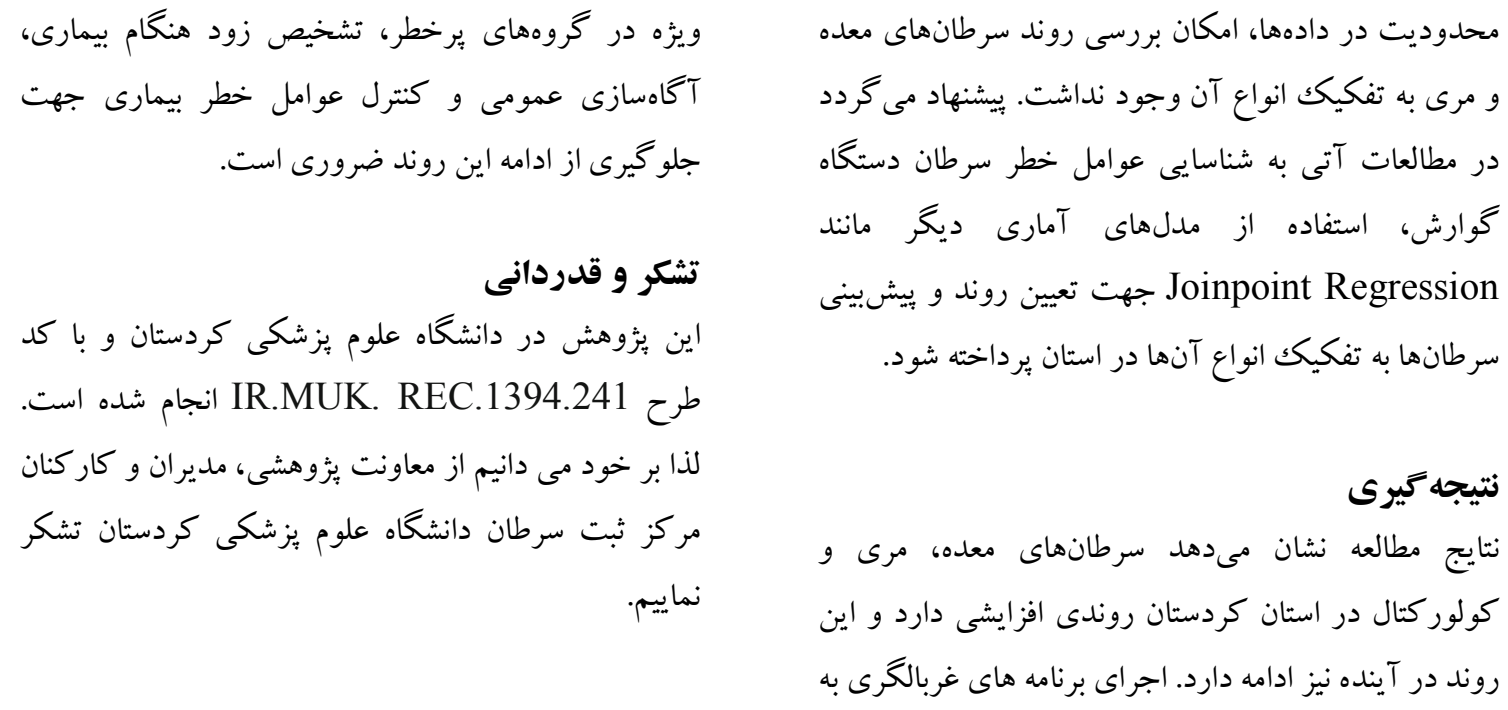

منابع

1. Ferlay J, Soerjomataram I, Dikshit R, Eser S, Mathers C, Rebelo M, et al. Cancer incidence and mortality worldwide: sources, methods and major patterns in GLOBOCAN 2012. Int J cancer. 2015;136(5):359-86.

2. Torre LA, Siegel RL, Ward EM, Jemal A. Global cancer incidence and mortality rates and trends-an update. Cancer Epidemiol Biomarkers Prev. 2016;25(1):16-27.

3. Malekzadeh R, Sadjadi AR. Review of esophagus cancer in Iran. Govaresh. 2008;13(1):25-34.

4. Atrkar-Roushan Z, Kazemnejad A, Mansour Ghanaei F, Zayeri F. Trend analysis of gastrointestinal cancer incidences in Guilan province: comparing rates over 15 years. Asian Pac J Cancer Prev. 2013;14(12):7587-93.

5. Moradpour F, Gholami A, Salehi M, Mansori K, Maracy MR, Javanmardi S, et al. Incidence, prevalence, and mortality rate of gastrointestinal cancer in Isfahan, Iran: application of the MIAMOD method. Asian Pac J Cancer Prev. 2016;17(3):11-5.

6. Mohebbi M, Mahmoodi M, Wolfe R, Nourijelyani K, Mohammad K, Zeraati H, et al. Geographical spread of gastrointestinal tract cancer incidence in the Caspian Sea region of Iran: spatial analysis of cancer registry data. BMC cancer. 2008;8(137):12. Available from: https:// doi:10.1186/1471-2407-8-137.

7. Naghibzadeh TA, Khanjani N, Yazdi Feyzabadi V, Varzandeh M, Haghdoost AA. Opium as a risk factor for upper gastrointestinal cancers: a population-based case-control study in Iran. Arch Iran Med. 2014;17(1):2-6.

8. Pourhoseingholi MA, Fazeli Z, Ashtari S, Bavand-Pour FSF. Mortality trends of gastrointestinal cancers in Iranian population. Gastroenterol Hepatol Bed Bench. 2013;6(1):52-7.

9. Mousavi SM, Gouya MM, Ramazani R, Davanlou M, Hajsadeghi N, Seddighi Z. Cancer incidence and mortality in Iran. Ann Oncol. 2008;20(3):556-63.

10. Darabi M, Asadi Lari M, Motevalian SA, Motlagh A, Arsang-Jang S, Karimi Jaberi M. Trends in gastrointestinal cancer incidence in Iran, 2001-2010: a joinpoint analysis. Epidemiol Health. 2016;21:8. Available from: https://doi.org/10.4178/epih.e2016056 
11. Mousavi SM, Somi MH. Gastric cancer in Iran 1966-2006. Asian Pac J Cancer Prev. 2009;10(3):407-12.

12. Enayatrad M, Salehiniya H. Trends in Gastric Cancer Incidence in Iran. J Mazandaran Univ Med Sci. 2014;24(114):8-16.

13. Malekzadeh R, Derakhshan MH, Malekzadeh Z. Gastric cancer in Iran: epidemiology and risk factors. Arch Iran Med. 2009;2(6):576-83.

14. Rahimi Pordanjani S, Baeradeh N, Lotfi MH, Pourmohammadi B. Epidemiology of colorectal cancer: incidence, mortality, survival rates and risk factors. Razi J Med Sci. 2016;23(144):41-50.

15. Rafiemanesh H, Pakzad R ,Abedi M, Kor Y, Moludi J, Towhidi F, et al. Colorectal cancer in Iran: Epidemiology and morphology trends. EXCLI J. 2016;15:738-44.

16. Kolahdouzan SH, Sajadi AR, Ramard AR, Khademi. Five common cancers in Iran. Arch Iran Med. 2010;13(2):143-6.

17. Khodadost M, Yavari P, Khodadost B, Babaei M, Sarvi F, Khatibi SR, Barzegari S. Estimating the Esophagus Cancer Incidence Rate in Ardabil, Iran: A Capture-Recapture Method. Iran J Cancer Prev. 2016;9(1):6. Available from: https:// doi: 10.17795/ijcp3972.

18. Nasseri Q. Cancers and Prevention strategies. Iranian J Epidemiology. 2005;1(1\&2):1-8.

19. Yazdizadeh B, Jarrahi AM, Mortazavi H, Mohagheghi MA, Tahmasebi S, Nahvijo A. Time trends in the occurrence of major GI cancers in Iran. Asian Pac J Cancer Prev. 2005;6(2):130-4.

20. Colquhoun A, Arnold M, Ferlay J, Goodman K, Forman D, Soerjomataram I. Global patterns of cardia and non-cardia gastric cancer incidence in 2012. Gut. 2015;64(12):1881-8.

21. Yavari P. Epidemiology textbook of prevalent diseases in Iran. 3nd ed. Tehran: Gap, 2013:77-90.

22. Somi MH, Golzari M, Farhang S, Naghashi S, Abdollahi L. Gastrointestinal cancer incidence in East Azerbaijan, Iran: update on 5 year incidence and trends. Asian Pac J Cancer Prev. 2014;15(9):3945-9.

23. Haghdoost AA, Hosseini H, Chamani G, Zarei MR, Rad M, Hashemipoor M, Zahedi MJ, Darvish-Moghadam S. Rising incidence of adenocarcinoma of the esophagus in Kerman, Iran. Arch Iran Med. 2008;11(4):364-70.

24. Almasi Z, Rafiemanesh H, Salehiniya H. Epidemiology characteristics and trends of incidence and morphology of stomach cancer in Iran. Asian Pac J Cancer Prev. 2015;16(7):2757-61.

25. Sadjadi A, Malekzadeh R, Derakhshan MH, Sepehr A, Nouraie M, Sotoudeh M, et al. Cancer occurrence in Ardabil: results of a population-based cancer registry from Iran. Int J Cancer. 2003;107(1):113-8.

26. Haidari M, Nikbakht MR, Pasdar Y, Najafi F. Trend analysis of gastric cancer incidence in Iran and its six geographical areas during 2000-2005. Asian Pac J Cancer Prev. 2012;13(7):3335-41.

27. Reshadat S, Saeidi S, Zangeneh A, Ziapour A, Saeidi F, Ghasemi S, et al. A study of the lower gastrointestinal tract cancer with emphasis on gender and age of the patients in western Iran (Kermanshah) over 2006-2011. J Fundam Appl Sci. 2017;9(1):65-72.

28. Najafi F, Mozaffari HR, Karami M, Izadi B, Tavvafzadeh R, Pasdar Y. Trends in incidence of gastrointestinal tract cancers in Western Iran, 1993-2007. Iran Red Crescent Med J. 2011;13(11):805-10. 
29. Raeisi A, Jan-babaei GH, Malekzadeh R. Iranian annual of national cancer registration report 2008-2009. 1st ed. Tehran: Mirmah, 2019:33-46.

30. Khosravi Shadmani F, Ayubi E, Khazaei S, Sani M, Mansouri Hanis S, Khazaei S, Soheylizad M, Mansori K. Geographic distribution of the incidence of colorectal cancer in Iran: a population-based study. Epidemiol Health. 2017;39:6. Available from: https://doi.org/10.4178/epih.e2017020.

31. Abdifard E, Ghaderi S, Hosseini S, Heidari M. Incidence trends of colorectal cancer in the West of Iran during 2000-2005. Asian Pac J Cancer Prev. 2013;14(3):1807-11.

32. Baniasadi N, Moghtader E, Khajehkazemi R, Mohebbi E. Increasing trend in colorectal cancer incidence in the Southeast of Iran 2003-2013: A population based cancer registry study. Asian Pac J Cancer Prev. 2015;16(13):5257-60.

33. Dolatkhah R, Somi MH, Kermani IA, Ghojazadeh M, Jafarabadi MA, Farassati F, et al. Increased colorectal cancer incidence in Iran: a systematic review and meta-analysis. BMC public health. 2015;15(997):14. Available from: doi: 10.1186/s12889-015-2342-9.

34. Malekzadeh R, Bishehsari F, Mahdavinia M, Ansari R. Epidemiology and molecular genetics of colorectal cancer in Iran: a review. Arch Iranian Med. 2009;12(2):161-9.

35. Yavari P. Epidemiology textbook of prevalent diseases in Iran. 3nd ed. Tehran: Gap, 2013: 65-76.

36. Sadjadi A, Marjani H, Semnani Sh, Nasseri-Moghaddam S. Esophageal cancer in Iran: A Review. Middle East J Cancer. 2010;1(1):5-14.

37. Kamangar F, Malekzadeh R, Dawsey SM, Saidi F. Esophageal cancer in Northeastern Iran: a review. Arch Iran Med. 2007;10(1):70-82.

38. Semnani Sh, Sadjadi A, Fahimi S, Nouraie M, Naeimi M, Kabir J, et al. Declining incidence of esophageal cancer in the Turkmen Plain, eastern part of the Caspian Littoral of Iran: a retrospective cancer surveillance. Cancer Detect Prev. 2006;30(1):14-9. 